Running head: SOCIAL SUPPORT \& PHYSICAL ACTIVITY IN OLDER ADULTS

\title{
Social Support and Physical Activity in Older Adults: Identifying Predictors Using Data from the Canadian Longitudinal Study on Aging
}

\author{
Chantelle Zimmer $^{1}$ \& Meghan H. McDonough ${ }^{1}$ \\ ${ }^{1}$ Faculty of Kinesiology, University of Calgary, 2500 University Drive NW, Calgary, Alberta, \\ T2N 1N4 Canada
}

Correspondence concerning this article should be addressed to Meghan McDonough, Faculty of Kinesiology, University of Calgary, 2500 University Drive NW, Calgary, Alberta, T2N 1N4 Canada. Email: meghan.mcdonough@ucalgary.ca. Phone: 403-220-7211.

Manuscript has been published online as Ahead of Print: Accepted author manuscript version reprinted, by permission, from Journal of Aging and Physical Activity, 2021, https://doi.org/10.1123/japa.2020-0393. (C) Human Kinetics, Inc.

Acknowledgements: This research was made possible using the data collected by the Canadian Longitudinal Study on Aging (CLSA). Funding for the Canadian Longitudinal Study on Aging (CLSA) is provided by the Government of Canada through the Canadian Institutes of Health Research (CIHR) under grant reference: LSA 94473 and the Canada Foundation for Innovation. This research has been conducted using the CLSA Baseline Tracking Dataset version 3.5, Baseline Comprehensive Dataset version 4.1, and CLSA Sample Weights version 1.2, under Application ID 180605. The CLSA is led by Drs. Parminder Raina, Christina Wolfson and Susan Kirkland. This work was also supported by the Canadian Institutes of Health Research, O'Brien Institute for Public Health, and the Brenda Strafford Centre on Aging.

Disclaimer: The opinions expressed in this manuscript are the authors' own and do not reflect the views of the Canadian Longitudinal Study on Aging. 


\begin{abstract}
This study examined which of nine forms of social support were the strongest predictors of physical activity in older adults, and to what degree these associations were moderated by eight demographic indicators of groups at increased risk of social isolation. Baseline data from 21,491 adults aged 65 and older who were participants of the Canadian Longitudinal Study on Aging was analyzed using multiple regression. Greater social network size, social contact with network members, and participation in community-related activities predicted greater physical activity, whereas being in a domestic partnership and perceiving more tangible support to be available were negatively associated. The strength and direction of these associations varied by sex, living arrangement, and income. Given the findings, various forms of social support should be incorporated in physical activity interventions but tailored to meet the needs of different segments of the aging population.
\end{abstract}

Keywords: social support, physical activity, older adults, social isolation, CLSA 
The number of Canadian adults age 65 and over is growing rapidly (Government of Canada, 2014). Helping older adults engage in life opportunities that enhance their health and quality of life as they age is important as we prepare for an aging society (International Federation on Ageing, 2012). Physical activity is associated with improved physical and mental health, physical and cognitive functioning, and quality of life among older adults (Baker, Meisner, Logan, Kungl, \& Weir, 2009; Netz, Wu, Becker, \& Tenenbaum, 2005). It is recommended that older Canadians accumulate at least 150 minutes of moderate-to-vigorous physical activity and perform muscle strengthening activities at least twice weekly to achieve these benefits, as well as accumulate several hours of light physical activity daily (Canadian Society for Exercise Physiology, 2020). However, over $80 \%$ of older adults do not accumulate sufficient moderate-to-vigorous physical activity per week (Clarke, Colley, Janssen, \& Tremblay, 2019) and the prevalence of older adults performing muscle strengthening activities is inconclusive due to limited national data (ParticipACTION, 2019). Although older adults do accumulate on average 3.2 hours of light physical activity per day (Statistics Canada, 2017), obtaining some benefits to their health.

Older adults often face barriers to physical activity participation, most notably health conditions, fear of injury, cost, transportation, and safety concerns (Baert, Gorus, Mets, Geerts, \& Bautmans, 2011; Spiteri et al., 2019). Further compounding the physical activity participation of older adults may be social isolation. Social isolation is defined as low quantity and quality of contact with others and is a prominent issue facing older Canadians, particularly women, lesbian, gay, bisexual (LGB) ${ }^{1}$, ethnic minority, Indigenous, immigrant, living alone, caregiver, and low

\footnotetext{
${ }^{1}$ We chose to use the acronym LGB instead of the more inclusive acronym LGBTQI2S+ because the literature cited here, and the dataset used in the secondary analysis conducted in this study, focused on lesbian, gay, and bisexual individuals only.
} 
income individuals (Government of Canada, 2017). Most of these populations are less physically active than the general older adult population (e.g., Azagba \& Sharaf, 2014; Chad et al., 2005), and likely experience barriers that are wider reaching and more substantial due to their circumstances (Government of Canada, 2017). Social influences, particularly social support, can help alleviate barriers and enhance motivation though for physical activity (Brawley, Flora, Locke, \& Gierc, 2016). Social support refers to interpersonal interactions that help another person (Feeney \& Collins, 2015). Social support is positively correlated with physical activity behavior change and maintenance among older adults (McAuley, Jerome, Elavsky, Marquez, \& Ramsey, 2003; McMahon et al., 2017), indicating it may be an important mechanism underlying physical activity promotion for this population.

Social support is multi-dimensional and conceptualized many ways. It can include concepts that have emerged from multiple theoretical perspectives to reflect the presence of other people in one's life (e.g., marital/partner status, social network), interaction with other people (e.g., social contact, online communication, social participation), availability of support (e.g., perceived, received), support functions and behaviors (e.g., instrumental, emotional, informational, companionship), and general perceptions of or satisfaction with support (HoltLunstad \& Uchino, 2015; Williams, Barclay, \& Schmied, 2004). However, there is not an agreed upon, unified framework of social support that captures all of its complexity and is sensitive to context. While researchers in the field of physical activity have examined social support different ways, they rarely compare associations between the various forms of support and physical activity. Therefore, little is known about which forms of social support predict unique variance in physical activity and which forms have the strongest associations with physical activity. Whether the forms of social support that are most important for enabling physical activity varies for 
groups of older adults at increased risk of social isolation is also unknown. Understanding predictors of physical activity is vital for developing ways to effectively support physical activity behavior change and maintenance in older adults, and promote its positive health outcomes, especially for those who are disproportionately isolated and inactive.

Due to social support being operationalized different ways, we drew on a framework that classifies social relationship measures on a structural-functional continuum (Valtorta, Kanaan, Gilbody, \& Hanratty, 2016) to delineate forms of social support for this study. Structural characteristics focus on who people share a relationship with and the connection between these individuals. Such characteristics include the number, type, and diversity of people in one's social network (i.e., marital/partner status, social network) and frequency and duration of contact with these people (i.e., social contact, online communication, social participation). Functional characteristics focus on the qualitative and behavioral aspects of interactions between people. These characteristics refer to the nature and purpose of relationships, and their beneficial functions in terms of providing and receiving social support (i.e., perceived and received social support; instrumental, emotional, informational, companionship). There is evidence that many forms of social support that represent structural and functional characteristics of social relationships are significantly associated with physical activity among older adults.

Married older adults are more active than those who are not married (Gao, Fu, Li, \& Jia, 2015; Hughes, Mcdowell, \& Brody, 2008), however, this association may only hold for men (Espinel, Chau, van der Ploeg, \& Merom, 2015) or couples where both members are active (Booth, Owen, Bauman, Clavisi, \& Leslie, 2000; Cobb et al., 2016; Gellert, Ziegelmann, Warner, \& Schwarzer, 2011; Richards, Franks, McDonough, \& Porter, 2018). Having a large and diverse social network of family, friends, and neighbors (Kendrick et al., 2018; Litwin, 2003) 
and frequently socializing with them (Ho, Hawkley, Dale, Waite, \& Huisingh-Scheetz, 2018) has also been associated with greater physical activity. Though, the mode of social interaction may affect support. Frequency of contact with social network members appears to have a stronger association with physical activity when people connect in-person compared to on the telephone (Bertera, 2003), which might be the case for online communication too, since in-person contact is thought to provide opportunities for people to be active together. Older adults who interact with others through social activities outside the home are more active (Benedetti, Schwingel, \& De Lucena Torres, 2011; Carrapatoso, Cardon, Van Dyck, Carvalho, \& Gheysen, 2018).

The perceived availability of social support generally, and social support specifically for engaging in physical activity, tends to be positively associated with older adults' physical activity as well (Lindsay Smith, Banting, Eime, O’Sullivan, \& van Uffelen, 2017). Certain supportive behaviors like instrumental support, emotional support, and companionship seem to be beneficial. In terms of general support, older adults who believed they could rely on someone for financial support (Loprinzi \& Joyner, 2016) or had relationships with people they felt they could discuss anything with and who would help them cope with stress in their life (Rennemark, Lindwall, Halling, \& Berglund, 2009) were more likely to engage in moderate-to-vigorous and strenuous physical activity. With respect to support specific to physical activity, married older adult women were more active when their husbands showed care and concern for their desire to exercise, complimented them on their mastery of a skill, and engaged in physical activity with them (Ranby \& Aiken, 2016). Similarly, encouragement from family and friends to be physically active and their joint participation has been positively associated with walking and moderate-tovigorous physical activity (Bohm, Mielke, da Cruz, Ramires, \& Wehrmeister, 2016; Carlson et al., 2012; Shores, West, Theriault, \& Davison, 2009). 
Many researchers have tried to incorporate social elements into physical activity interventions for older adults to increase their efficacy, primarily via practices such as delivering exercise in a group format. But bringing people together is not necessarily sufficient for fostering social support and promoting adherence since it does not guarantee that supportive relationships will form, and the quality of social interactions is often left to chance (Floyd \& Moyer, 2010; Richards et al., 2018). Older adults more vulnerable to social isolation and exclusion may therefore be less likely to experience the social support they need. Further, research with adults under the age of 65 has shown that not all forms of social support promote engagement in physical activity (Scarapicchia, Amireault, Faulkner, \& Sabiston, 2016). Attempts to provide social support can have a negative impact if they are not responsive to the needs of the person (Feeney \& Collins, 2015); for instance, they are unwanted, pressuring, or controlling (Martire et al., 2013; McDonough, Sabiston, \& Ullrich-French, 2011). Participation in physical activity can be enabled through support that is tailored to the needs of the individual and target population.

The purpose of this study was two-fold: (1) to identify which forms of social support (marital/partner status, social network, social contact, online communication, social participation, tangible support, affectionate support, emotional/informational support, positive social interaction) predict physical activity in adults 65 years and older and (2) to examine to what degree the associations between the forms of social support and physical activity are moderated by demographic indicators of groups at increased risk of social isolation (sex, sexual orientation, race/ethnicity, Indigenous identity, immigrant, living alone, caregiver, income). It was hypothesized that all forms of support would be positively associated with physical activity in older adults. However, examining which forms of social support would predict unique variance in physical activity and which forms would be stronger predictors than others was exploratory 
given the lack of theory and empirical literature comparing the relative strength of multiple forms of social support in predicting physical activity. Similarly, given the lack of empirical literature addressing the relative importance of different forms of social support in predicting physical activity for groups of older adults at increased risk of social isolation, there were not specific hypotheses about which demographic indicators would significantly moderate the associations, or the strength and direction of any moderator effects. Data from the Canadian Longitudinal Study on Aging (CLSA) was used for this study because the number and variety of social support variables available enabled us to address the first research objective, and the large number of participants sampled from populations considered at increased risk of social isolation allowed us to address the second research objective.

\section{Methods}

\section{Data Source and Participants}

Ethics approval was obtained from our University's Conjoint Health Research Ethics Board to perform a secondary analysis using baseline data from the CLSA. The purpose of the CLSA is to collect information on factors related to aging from a population-based sample of 51,338 Canadian men and women, aged 45 to 85 at baseline, over at least 20 years to understand determinants and improve health outcomes (Raina et al., 2009). The CLSA research team obtained ethical approval to conduct this study before undertaking participant recruitment and data collection from 2010 to 2015. Potential participants were mailed an information package outlining the study and asked to provide written informed consent if interested in participating. The CLSA consists of two cohorts of participants. Participants in the Tracking cohort were selected, using a complex survey design, across 10 provinces in which 21,421 completed a computer-assisted telephone interview. Participants in the Comprehensive cohort were selected, 
using a complex survey design, from within a 25- to 50-kilometre radius of a data collection site across seven provinces (British Columbia, Alberta, Manitoba, Ontario, Quebec, Nova Scotia, Newfoundland and Labrador). A trained research personnel visited the homes of 30,097 participants to conduct the computer-assisted questionnaire in person, and participants were invited to visit the data collection site for additional clinical and physical assessments. Participants included in the CLSA were those who lived in a household or transitional dwelling, such as a senior residence in which minimal care was provided. Participants excluded from the study were those who lived in the three territories, certain remote regions, on federal First Nation reserves and other settlements, in long-term care facilities at the time of recruitment, were fulltime members of the Canadian Armed Forces, temporary visa holders, unable to respond in English or French, had cognitive impairments at the time of recruitment, or had transitional health coverage. Data from participants aged 65 and older in each cohort were included in the analyses $(N=21,491)$.

\section{Measures}

Social support. Nine forms of social support were examined as predictor variables. Forms of support that reflected the presence of other people in one's life (marital/partner status, social network) and interaction with other people (social contact, online communication, social participation) were considered structural characteristics, and the availability of social support and support behaviors (tangible support, affectionate support, emotional/informational support, positive social interaction) were considered functional characteristics (see Figure 1). Items in the CLSA dataset pertaining to these forms of support are widely used in the literature and came from various sources. Items adapted from the General Social Survey (Cycles 1, 5, 11, 16) provided data on social network, social contact, and online communication, items from the 
Canadian Community Health Survey (Cycle 4.2 - Healthy Aging) and the English Longitudinal Study of Aging provided data on social participation, and items from the Medical Outcomes Study (MOS) Social Support Survey (Sherbourne \& Stewart, 1991) provided data on tangible support, affectionate support, emotional/informational support, and positive social interaction. Data collection for national surveys typically occurs at regular intervals, with different waves of data collection denoted by cycle numbers.

Presence of other people.

Marital/partner status. Participants were categorized as not in a domestic partnership (0) if they were single, never married, never lived with a partner, widowed, or divorced, or in a domestic partnership (1) if they were married or living with a partner.

Social network. Participants reported the number of children, siblings, relatives, friends, and neighbors they had, as well as people they knew through work or school, community involvement, and other activities. Responses to these items were summed to calculate total social network size, which ranged from 0 to 650 .

\section{Interaction with other people.}

Social contact. Participants indicated when they last got together with their children, siblings, relatives, friends, and neighbors who lived outside the household $(0=$ more than one year ago, $1=$ within the past year, $2=$ within the past six months, $3=$ within the past month, $4=$ within the last week or two, $5=$ within the last day or two).

Online communication. Participants rated how often they used social networking sites to make new friends, stay in touch or make plans with friends, stay in touch or make plans with family, and promote themselves or their work $(0=$ never, $1=$ a few times a year, $2=$ a few times a month, 3 = a few times $a$ week, $4=$ daily). To capture online social interaction with network 
members, the last item was removed. A confirmatory factor analysis was conducted with the remaining three items since they do not come from an established measure. The results indicated the items were part of a single factor. Mean responses to the items were calculated to determine average frequency of online communication with family and friends.

Social participation. Participants reported how often in the past 12 months they participated in family or friend activities outside the household, church or religious activities, sport or physical activities with others, educational or cultural activities, clubs or fraternal organization activities, neighbourhood, community, or professional association activities, volunteer or charity activities, and recreational activities with others $(0=$ did not participate, $1=$ at least once a year, 2 = at least once a month, 3 = at least once a week, $4=$ at least once a day).

\section{Availability of social support and support behaviors.}

Participants indicated how often $(1=$ none of the time, $2=$ a little of the time, $3=$ some of the time, $4=$ most of the time, $5=$ all of the time) the following perceived support was available: tangible support (e.g., had someone to help with daily chores if they were sick), affectionate support (e.g., someone who showed them love and affection), emotional and informational support (e.g., had someone to give information to help them), and positive social interaction (e.g., had someone to do something enjoyable with). A score was obtained for each subscale by calculating the average response to all items in the subscale. The score was then transformed to a scale of 0 to 100 using the formula: 100 x ((observed score - minimum possible score) / (maximum possible score - minimum possible score)) (RAND Healthcare, n.d.).

Physical activity. Items from the Physical Activity Scale for the Elderly (PASE; Washburn, Smith, Jette, \& Janney, 1993) were used to examine total physical activity as the outcome variable. The PASE was developed to measure participation in 12 physical activities, 
across three domains, during the past week among adults 65 years and older. For the leisure-time domain, participants were asked how often $(0=$ never, $1=$ seldom, $2=$ sometimes, $3=$ often $)$ and for how long $(1=$ less than an hour, 2 = one to two hours, $3=$ two to four hours, $4=$ more than four hours) they participated in walking, light recreational activities, moderate recreational activities, strenuous recreational activities, and muscle strength/endurance activities. For the household domain, participants were asked to report if they had done $(0=n o, 1=y e s)$ light housework, heavy housework, home repairs, lawn work or yard care, outdoor gardening, or cared for another person. Participants were provided multiple examples for each of the different intensities of recreational activities and housework to guide their responses. For the occupational domain, participants were asked if they worked for pay or as a volunteer $(1=n o, 2=y e s)$, how many hours per week they worked or volunteered (0-168), and the amount of physical activity required for their job or volunteer work $(1=$ mainly sitting, $2=$ sitting and standing with some walking, $3=$ walking and light manual work, $4=$ walking and heavy manual work). A total physical activity score was calculated for participants by multiplying their daily average time spent in each activity by an intensity weight and summing all 12 values. Total scores can range from 0 to over 400 (Washburn et al., 1993).

Covariates. Sixteen demographics and health factors that could influence the associations between social support and physical activity served as covariates. Participants included in the current study were 65 years or older and indicated their highest level of education $(0=$ less than secondary school graduation, 1 = secondary school graduation/no post-secondary education, 2 = some post-secondary education, 3 = post-secondary degree/diploma). Body mass index was calculated based on their height and weight. They rated their general and mental health $(0=$ poor, $1=$ fair, $2=$ good, $3=$ very good, $4=$ excellent $)$ and indicated how often they 
experienced symptoms of depression, in which the overall score ranged from 0 to 30 .

Participants also reported whether a doctor ever told them they had one of many chronic conditions, with the maximum number being 39, and whether they were usually free of pain and discomfort $(0=$ yes, $1=n o)$, had sustained a serious injury in the past 12 months that limited normal activities $(0=n o, 1=y e s)$, and experienced a fall in the last year $(0=n o, 1=y e s)$. They were categorized based on their smoking habits $(0=$ never smoked, $1=$ non-smoker now, but former occasional smoker, 2 = non-smoker now, but former daily smoker, 3 = occasional smoker now, but never a daily smoker, 4 = occasional smoker now, but a former daily smoker, 5 = daily smoker $)$ and alcohol consumption within the last 12 months $(0=$ did not drink, $1=$ occasional drinker, 2 = regular drinker). Participants indicated where on a 10-step ladder they stood in their local community and their retirement status $(0=$ not retired, $1=$ partly retired, $2=$ completely retired). Lastly, they reported what prevented them from participating in more social, recreational, or group activities in the past 12 months, with the total number of barriers being 19, and what prevented them from participating in more physical activities in the same time span, with the maximum number of barriers being 13.

\section{Demographic indicators of groups at increased risk of social isolation. Eight}

demographic indicators of older adults at increased risk of social isolation were examined as moderator variables. Participants were categorized as male (0) or female (1), heterosexual (0) or LGB (1), Caucasian (0) or non-Caucasian (1), non-Indigenous (0) or Indigenous (1), not an immigrant (0) or an immigrant (1), not living alone (0) or living alone (1), and not a caregiver (0) or a caregiver (1) based on self-report questions. Caregivers in this study were older adults who provided assistance to another person due to a health condition, but not as part of their paid 
or volunteer work. The following scale was used for income: (0) less than $\$ 20,000$, (1) $\$ 20,000$ to $\$ 50,000$, (2) $\$ 50,000$ to $\$ 100,000$, (3) $\$ 100,000$ to $\$ 150,000$, and (4) $\$ 150,000$ or more.

\section{Data Analysis}

Preliminary data analyses. SPSS version 26 was used to perform preliminary analyses. More than $5 \%$ of data were missing for average frequency of online communication with family and friends (26.30\%), total physical activity (7.00\%), pain and discomfort (7.20\%), falls (7.10\%), social inequality (11.90\%), barriers to participating in more physical activities $(7.40 \%)$, and income $(8.90 \%)$. All of these variables except income were part of a supplemental questionnaire administered to participants at least two years after the start of baseline data collection. While there was only .90 to $3.40 \%$ of missing data for the social support behaviors, person-mean substitution was used for participants who responded to at least $50 \%$ of items for each subscale (Hawthorne \& Elliott, 2005). A confirmatory factor analysis and internal consistency reliability check demonstrated that the subscales were a good fit to the specified model. Preliminary analyses also indicated the data was missing at random: missingness was more likely to occur among participants with smaller social networks, who communicated online with family and friends less frequently, had lower perceived social support, were less physically active, were older, had lower education, had poorer perceived general and mental health, experienced symptoms of depression more frequently, smoked more often, drank alcohol less often, and had lower income. Six variables with skewness and kurtosis values greater than \pm 2.00 (Miles \& Shevlin, 2001) and 847 cases with Mahalanobis distance values greater than 65.25 (Tabachnick \& Fidell, 2013) were detected. To address these issues of missing data and nonnormality, a maximum likelihood estimator with robust standard errors was chosen for our 
primary analyses. The final model was also examined with and without the multivariate outliers to determine whether including them affected the conclusions.

Primary data analyses. The CLSA developed sampling weights to adjust for unequal probabilities in certain groups of the population being selected to participate. The CLSA recommends inflation weights be used to estimate descriptive parameters and analytic weights be used to examine relationships between variables (Canadian Longitudinal Study on Aging, 2020). Following these suggestions, inflation weights were applied to the data in SPSS to compute descriptive statistics, whereas analytic weights were applied to calculate bivariate correlations. Analytic weights were also applied to the data in Mplus version 8.4 when performing linear multiple regression analyses with the MLR estimator to answer our two research questions. The significance level for all analyses was .05.

Research question 1. Model 1 examined which of the nine forms of social support significantly predicted physical activity, while controlling for 16 demographics and health factors. Confidence intervals for the difference between regression coefficients of significant predictors were calculated to determine which forms of support were stronger predictors of physical activity than others (Cohen, Cohen, West, \& Aiken, 2003).

Research question 2. In order to determine the degree to which the eight demographic indicators of groups at increased risk of social isolation moderated the associations between the forms of social support and physical activity, separate models were first conducted for each predictor variable, moderator variable, and two-way interaction term. Due to the small and very uneven split between categories for sexual orientation, race/ethnicity, and Indigenous identity, the majority of models that included these moderator variables would not run so we were unable to examine their interactions with all the forms of support. However, the models that ran yielded 
four significant interaction effects. The nine predictor variables, eight moderator variables, and four interaction terms were subsequently entered in Model 2 to examine significant main and interaction effects on physical activity. When Model 2 was run with and without multivariate outliers, the same conclusions were reached so the results with all cases are reported. Significant interactions were graphed using $\mathrm{R}$ version 3.6.3 to interpret the strength and direction of the associations between forms of social support and physical activity across groups at increased risk of social isolation.

\section{Results}

\section{Description of Study Participants}

Participants ranged in age from 65 to 89 years $(M=72.78, S D=5.71)$ and primarily resided in the core of an urban population centre (75.13\%) in Ontario (21.88\%), Quebec (18.34\%), or British Columbia (17.26\%). The majority of participants had a spouse or partner (67.90\%), fairly large social network $(M=146.56, S D=98.58)$, interacted frequently with social network members $(M=4.63, S D=.64)$ but not online $(M=.70, S D=1.02)$, participated frequently in community-related activities $(M=2.94, S D=.69)$, had relatively high perceptions of tangible support $(M=81.83, S D=21.69)$, affectionate support $(M=86.20, S D=20.40)$, emotional/informational support $(M=79.37, S D=20.84)$, and positive social interaction $(M=$ $82.34, S D=20.64)$, and were moderately physically active $(M=115.01, S D=58.38)$. There was a comparable percentage of participants who were male $(46.60 \%)$ and female $(53.40 \%)$, but most participants were heterosexual (98.50\%), Caucasian (96.20\%), non-Indigenous (96.40\%), nonimmigrants (82.10\%), not living alone (74.10\%), non-caregivers (59.80\%), and had an annual household income between $\$ 20,000$ and $\$ 50,000$ (41.60\%) or $\$ 50,000$ and $\$ 100,000(30.30 \%)$. 
Many participants completed at least some post-secondary education (51.80\%), were retired $(79.50 \%)$, and felt they had modest social standing in their local community $(M=5.56$, $S D=2.16)$. They perceived their general health to be good or very good $(68.50 \%)$ and their mental health to be very good or excellent (68.40\%). A large proportion were non-smokers (92.00\%), typically experienced no pain $(50.20 \%)$, had not sustained an injury $(90.60 \%)$ or fall $(79.40 \%)$ in the past year, and on average had relatively few chronic conditions $(M=5.11, S D=$ 3.14) and symptoms of depression in the past week $(M=5.50, S D=4.56)$. Though, the majority of participants were regular alcohol drinkers (63.80\%) and body mass index scores indicated that on average they were slightly overweight $(M=27.63, S D=5.09)$. Participants reported that very few barriers prevented them from participating in more social, recreational, group $(M=.46, S D=$ $.83)$ and physical activities $(M=.56, S D=.76)$ within the last year.

\section{Associations Between Forms of Social Support and Physical Activity}

Bivariate correlations for the predictor, moderator, and outcome variables can be found in Table 1. All forms of social support had a positive and significant bivariate association with physical activity, except for average frequency of online communication with family and friends. Nearly all covariates also had a significant association with physical activity, though the direction of these correlations varied: age $(r=-.23)$, education $(r=.09)$, body mass index $(r=-$ $.10)$, general health $(r=.23)$, general mental health $(r=.12)$, depression $(r=-.15)$, chronic conditions $(r=-.23)$, pain and discomfort $(r=-.11)$, falls $(r=-.07)$, smoking habits $(r=-.02)$, alcohol use $(r=.10)$, social inequality $(r=.13)$, retirement status $(r=-.20)$, barriers to participating in more physical activities $(r=-.09)$. Only injuries and barriers to participating in more social, recreational, or group activities were not significantly associated. 
Research question 1. Model 1 was statistically significant and explained $21 \%$ of the variance in physical activity (see Table 2). Total social network size, frequency of contact with social network members, and frequency of participation in community-related activities were positively and significantly associated with physical activity, whereas being in a domestic partnership and tangible support were negatively associated. Average frequency of online communication with family and friends, affectionate support, emotional and informational support, and positive social interaction were not significant predictors in this model. The results from the confidence interval calculations indicated that the upper and lower limits for all combinations of the significant forms of social support included zero, indicating that certain forms of support were not stronger predictors of physical activity than others.

Research question 2. Model 2 yielded seven significant main effects and four interaction effects (see Table 2). Significant main effects were observed for total social network size, frequency of contact with social network members, sexual orientation, race/ethnicity, Indigenous identity, immigrant, and caregiver. Older adults with larger social networks and greater frequency of contact with social network members had higher physical activity levels than those with smaller social networks and lower frequency of contact with network members. Older adults who self-reported as LGB and non-Caucasian had lower physical activity levels than heterosexual and Caucasian older adults, while those who self-reported as Indigenous, immigrants, and caregivers were more physically active than non-Indigenous, non-immigrant, and non-caregiver older adults.

The significant interaction effects are illustrated in Figure 2. There was an association between marital/partner status and physical activity, which was negative for females and positive for males (Figure 2a). However, only the slope for females was significant, meaning that women 
in a partnership had lower physical activity levels than women not in a partnership. A positive association between social participation and physical activity was evidenced for both older adults not living and living alone (Figure 2b). Older adults who participated more frequently in community-related activities had higher physical activity levels than those who participated less frequently, regardless of their living arrangement, though the effect was enhanced for older adults not living alone. The association between tangible support and physical activity was negative and significant for older adults not living alone and non-significant for older adults living alone (Figure 2c). Older adults who did not live alone and perceived more tangible support to be available had lower physical activity levels than those who perceived less tangible support to be available. And last, there was a negative association between online communication and physical activity for older adults at all income levels (Figure 2d). The slope was only significant for those with low income though, indicating that older adults with low income who communicated online more frequently with family and friends had lower physical activity levels than those who communicated online less frequently.

\section{Discussion}

The results of this study provide some support for our hypothesis that all nine forms of social support would be positively associated with physical activity among older adults, and builds on prior research by demonstrating the importance of having other people present in one's life, interacting with others, and perceiving certain social support to be available. In contrast to the literature though, online communication, affectionate support, emotional and informational support, and positive social interaction did not predict unique variance in physical activity when included in a model with other forms of social support. Studies that have used existing social networking sites, such as Facebook and Twitter, to target physical activity behavior among 
younger adults have shown positive results (Joseph-Shehu, Ncama, Mooi, \& MashambaThompson, 2019; Laranjo et al., 2015; Maher et al., 2014; Petersen, Prichard, \& Kemps, 2019). While more research on this topic is needed, the use of these sites in intervention research may produce more favorable outcomes than social network platforms and software programs specifically designed to change health behaviors because they can address issues of reach, engagement, and retention (Maher et al., 2014; Petersen et al., 2019). Further, when social networking sites are used to foster social support, friendly competition, or provide personalized feedback, the effects are enhanced (Yang, 2017). However, a paucity of research includes older adults and focuses on "regular" use of social networking sites. Only 56\% of Canadian older adults use these sites (Statistics Canada, 2019), with the majority of participants in the current study using them a few times a year or less to interact with family and friends, which might explain our finding.

The discrepancy in results for the other aforementioned forms of support might be attributed to how they were conceptualized. The supportive behaviors included in this study focused on general support, not support specific to physical activity (Bohm et al., 2016; Carlson et al., 2012; Ranby \& Aiken, 2016; Shores et al., 2009) which might have a stronger association (Lindsay Smith et al., 2017). The items that comprised affectionate support, emotional and informational support, and positive social interaction also emphasized whether the person perceived someone to be available to provide support, rather than measuring the number of people who could provide support (Rennemark et al., 2009) or frequency of support offered or received (Bohm et al., 2016; Carlson et al., 2012; Ranby \& Aiken, 2016). When the results related to the first research question are considered together, more forms of social support that represented the structural versus functional characteristics of social relationship measures were 
significant predictors of physical activity. While these forms of support came from distinct sources and added unique variance to physical activity, they seem to be equally important. However, three demographic indicators of groups at increased risk of social isolation moderated these associations.

The results pertaining to the second research question indicated that the strength and direction of the associations between particular forms of social support that reflected the presence of other people in one's life, interaction with other people, and availability of social support and physical activity varied by sex, living arrangement, and income. Marital/partner status and tangible support had a positive bivariate association with physical activity, but a negative multivariate association due to their interaction with certain moderators. Differences in the physical activity of married older adult men and women have been well documented (e.g., Espinel et al., 2015). Incongruent with previous research, a statistically significant association was not evidenced for men, but our finding that women in a partnership were less physically active than women not in a partnership complements the literature. Espinel and colleagues (2015) speculate that this difference might be explained by traditional societal roles, in which household and caregiving activities could be barriers to physical activity for married women. Similarly, researchers have compared the physical activity of older adults with different living arrangements (e.g., Yu, Hou, \& Miller, 2018), though little is known about the association between tangible support and physical activity. Perrino et al. (2011), however, found that older adults with more depressive symptoms walked fewer blocks if they received higher levels of support with day-to-day activities. Tangible support behaviors in this study focused on help with daily living tasks, including support when confined to a bed and with meal preparation, chores, and visits to the doctor. Older adults not living alone who perceived greater tangible support to 
be available may have had lower physical activity levels than those who perceived less tangible support to be available because these individuals required more help from household members. Feeney and Collins (2015) have suggested that general perceptions of social support arise from numerous instances of specific support being provided by others. Therefore, the need for greater support with daily living tasks among older adults not living alone may have adversely influenced their physical activity.

Prior research suggests that older adults who interact with social network members more often have higher physical activity levels, but that the strength of this association may differ depending on the mode of interaction (Bertera, 2003; Ho et al., 2018). Further, the nature of social interactions can also influence physical activity (e.g., reason for interaction, type of support seeking). The positive association between social participation and physical activity is consistent with the literature on the general population of older adults (Benedetti et al., 2011; Carrapatoso et al., 2018), though this association was strongest for those not living alone. Older adults not living alone might participate more frequently in community-related activities than those living alone because of the presence of household members. People may feel more comfortable attending social activities with others than by themselves, increasing the likelihood of older adults not living alone participating in such activities. These opportunities might also be used to bond with household members. However, more research is needed to understand this association. Conversely, a negative association between online communication and physical activity was found for older adults with low income. It seems logical that older adults who communicate more frequently with family and friends online would have greater bouts of physical inactivity, impacting their total physical activity levels. While research has found that people with lower income are less likely to have access to the Internet (Hong, Zhou, Fang, \& 
Shi, 2017; Statistics Canada, 2019), there appear to be no significant differences in the use of social networking sites between people with lower and higher income (Kontos, Emmons, Puleo, \& Viswanath, 2010). Why this association was only statistically significant for older adults with low income is unclear and therefore, warrants further investigation.

Taken together, the moderation results demonstrated that living arrangement seems to play an important role in the association between multiple forms of social support and physical activity for older adults relative to other demographic indicators of groups at increased risk of social isolation. More forms of social support that reflected the structural characteristics of social relationship measures were also moderated by these demographic indicators than forms that reflected functional characteristics. We recommend that researchers interested in examining associations between social support and physical activity among older adults, as well as moderators that influence these associations, control for a number of variables based on our findings. These variables include age, body mass index, general health, general mental health, chronic conditions, falls, smoking habits, social inequality, retirement status, and barriers to participating in more social, recreational, group, and physical activities.

\section{Limitations}

Baseline data from the CLSA was used to examine our research questions, but some limitations related to the dataset should be noted. During our preliminary data analyses, we found large amounts of missing data for several variables. However, we attempted to minimize the effect of missing data on our results using robust analytical methods. Study participants were also not recruited from federal First Nation reserves and settlements, with indicators of Indigenous identity based on self-report, and participants mainly resided in urban areas. This limits the generalizability of our findings to older adults who self-identify as Indigenous and live 
in urban areas. The social support variables were not comprehensive of the forms and measures of social support in the literature. This study therefore only provides initial evidence of some forms of social support that predict unique variance in physical activity among older adults. These variables also captured older adults' perceptions of general social support available to them instead of support specific to physical activity. A recent systematic review yielded stronger evidence for the association between specific social support and physical activity among older adults compared to general support (Lindsay Smith et al., 2017), although, this study suggests there is a positive association for certain forms of general support. The outcome variable focused on total physical activity as well, rather than specific physical activity intensity levels (i.e., moderate-to-vigorous) known to be correlated with greater health benefits. How associations between the different forms of social support and physical activity varied for certain groups (i.e., LGB, ethnic minority, and Indigenous older adults) could not be determined because of very unbalanced samples either. Due to the exploratory nature of our research questions, further research is needed to replicate and extend our findings.

\section{Conclusion}

This study makes a significant contribution to the aging and physical activity literature by comparing the effects of multiple forms of social support on the physical activity of a large sample of older adults, and exploring the degree to which these effects vary by different demographic indicators of groups at increased risk of social isolation. The main finding of this research was that five distinct forms of social support predicted the physical activity levels of adults 65 years and older, indicating important conceptual implications. Social support is a multidimensional concept. Most of the forms of support included in this study, which represented some of its dimensions, were statistically associated with physical activity, reinforcing the need 
for a comprehensive conceptual framework of social support to guide research in this field. Although the effect sizes were small, the findings also indicated that these forms of support largely had a positive association with physical activity, warranting their inclusion in physical activity promotion efforts targeting the aging population. However, the results demonstrated that certain groups of older adults at increased risk of social isolation have different social support needs for physical activity. Physical activity interventions should be tailored to the needs of these segments of the population to increase their participation and afford them greater opportunities to obtain health benefits associated with an active lifestyle. 


\section{References}

Azagba, S., \& Sharaf, M. F. (2014). Physical inactivity among older Canadian adults. Journal of Physical Activity and Health, 11(1), 99-108. doi: 10.1123/jpah.2011-0305

Baert, V., Gorus, E., Mets, T., Geerts, C., \& Bautmans, I. (2011). Motivators and barriers for physical activity in the oldest old: A systematic review. Ageing Research Reviews, 10(4), 464-474. doi: 10.1016/j.arr.2011.04.001

Baker, J., Meisner, B. A., Logan, A. J., Kungl, A., \& Weir, P. (2009). Physical activity and successful aging in Canadian older adults. Journal of Aging and Physical Activity, 17(2), 223-235.doi: 10.1123/japa.17.2.223

Benedetti, T. R., Schwingel, A., \& De Lucena Torres, T. (2011). Physical activity acting as a resource for social support among older adults in Brazil. Journal of Human Sport and Exercise, 6(2), 452-461. doi: 10.4100/jhse.2011.62.26

Bertera, E. M. (2003). Physical activity and social network contacts in community dwelling older adults. Activities, Adaptation \& Aging, 27(3-4), 113-127. doi: 10.1300/J016v27n03_08

Bohm, A. W., Mielke, G. I., da Cruz, M. F., Ramires, V. V., \& Wehrmeister, F. C. (2016). Social support and leisure-time physical activity among the elderly: A population-based study. Journal of Physical Activity and Health, 13(6), 599-605. doi: 10.1123/jpah.2015-0277

Booth, M. L., Owen, N., Bauman, A., Clavisi, O., \& Leslie, E. (2000). Social-cognitive and perceived environment influences associated with physical activity in older Australians. Preventive Medicine, 31(1), 15-22. doi: 10.1006/pmed.2000.0661

Brawley, L. R., Flora, P. K., Locke, S. R., \& Gierc, M. S. H. (2016). Social influence in promoting change among older adults: Group-mediated cognitive behavioral interventions. Kinesiology Review, 5(1), 39-49. doi: 10.1123/kr.2015-0051 
Canadian Longitudinal Study on Aging. (2020). CLSA technical document 2020: Sampling and computation of response rates and sample weights for the tracking (telephone interview) participants and comprehensive participants. Retrieved from https://www.clsa-elcv.ca/ Canadian Society for Exercise Physiology. (2020). Canadian 24-hour movement guidelines for adults 65 years or older: An integration of physical activity, sedentary behaviour, and sleep. Retrieved from https://csepguidelines.ca/

Carlson, J. A., Sallis, J. F., Conway, T. L., Saelens, B. E., Frank, L. D., Kerr, J.,...King, A. C. (2012). Interactions between psychosocial and build environment factors in explaining older adults' physical activity. Preventive Medicine, 54(1), 68-73. doi: 10.1016/j.ypmed.2011.10.004

Carrapatoso, S., Cardon, G., Van Dyck, D., Carvalho, J., \& Gheysen, F. (2018). Walking as a mediator of the relationship of social support with vitality and psychological distress in older adults. Journal of Aging and Physical Activity, 26(3), 430-437. doi: 10.1123/japa.2017-0030

Chad, K. E., Reeder, B. A., Harrison, E. L., Ashworth, N. L., Sheppard, S. M., Schultz, S. L.,...Lawson, J. A. (2005). Profile of physical activity levels in community-dwelling older adults. Medicine \& Science in Sports \& Exercise, 37(10), 1774-1784. doi: 10.1249/01.mss.0000181303.51937.9c

Clarke, J., Colley, R., Janssen, I., \& Tremblay, M. S. (2019). Accelerometer-measured moderateto-vigorous physical activity of Canadian adults, 2007 to 2017. Health Reports, 30(8), 310. doi: 10.25318/82-003-x201900800001-eng 
Cobb, L. K., Godino, J. G., Selvin, E., Kucharska-Newton, A., Coresh, J., \& Koton, S. (2016). Spousal influence on physical activity in middle-aged and older adults: The ARIC study. American Journal of Epidemiology, 183(5), 444-451. doi: 10.1093/aje/kwv104

Cohen, J., Cohen, P., West, S. G., \& Aiken, L. S. (2003). Applied multiple regression/correlation analysis for the behavioral sciences (3rd ed.). Mahwah, NJ: Lawrence Erlbaum Associates Publishers.

Espinel, P. T., Chau, J. Y., van der Ploeg, H. P., \& Merom, D. (2015). Older adults' time in sedentary, light and moderate intensity activities and correlates: Application of Australian time use survey. Journal of Science and Medicine in Sport, 18(2), 161-166. doi: 10.1016/j.jsams.2014.02.012

Feeney, B. C., \& Collins, N. L. (2015). A new look at social support: A theoretical perspective on thriving through relationships. Personality and Social Psychology Review, 19(2), 113147. doi: $10.1177 / 1088868314544222$

Floyd, A., \& Moyer, A. (2010). Group versus individual exercise interventions for women with breast cancer: A meta-analysis. Health Psychology Review, 4(1), 22-41. doi: $10.1080 / 17437190903384291$

Gao, J., Fu, H., Li, J., \& Jia, Y. (2015). Association between social and built environments and leisure-time physical activity among Chinese older adults: A multilevel analysis. BMC Public Health, 15(1), 1317. doi: 10.1186/s12889-015-2684-3

Gellert, P., Ziegelmann, J. P., Warner, L. M., \& Schwarzer, R. (2011). Physical activity intervention in older adults: Does a participating partner make a difference? European Journal of Ageing, 8(3), 211-219. doi: 10.1007/s10433-011-0193-5 
Government of Canada. (2014). Report on the social isolation of seniors, 2013-2014 (ESDC Catalogue No. SSD-138-12-14). Retrieved from https://www.canada.ca/en/nationalseniors-council/programs/publicationsreports/ 2014/social-isolation-seniors.html

Government of Canada. (2017). Who's at risk and what can be done about it? A review of the literature on the social isolation of different groups (ESDC Catalogue No. SSD-183-0217E). Retrieved from https://www.canada.ca/en/national-seniorscouncil/programs/publications-reports/2017/review-social-isolation-seniors.html

Hawthorne, G., \& Elliott, P. (2005). Imputing cross-sectional missing data: Comparison of common techniques. Australian and New Zealand Journal of Psychiatry, 39(7), 583-590. doi: 10.1111/j.1440-1614.2005.01630.x

Ho, E. C., Hawkley, L., Dale, W., Waite, L., \& Huisingh-Scheetz, M. (2018). Social capital predicts accelerometry-measured physical activity among older adults in the U.S.: A cross-sectional study in the national social life, health, and aging project. BMC Public Health, 18(1), 804. doi: 10.1186/s12889-018-5664-6

Holt-Lunstad, J., \& Uchino, B. N. (2015). Social support and health. In K. Glanz, B. K. Rimer, \& K. Viswanath (Eds.), Health behavior: Theory, research, and practice (pp. 183-204). San Francisco, CA: Jossey-Bass.

Hong, Y. A., Zhou, Z., Fang, Y., \& Shi, L. (2017). The digital divide and health disparities in China: Evidence from a national survey and policy implications. Journal of Medical Internet Research, 19(9), e317. doi: 10.2196/jmir.7786

Hughes, J. P., Mcdowell, M. a., \& Brody, D. J. (2008). Leisure-time physical activity among US adults 60 or more years of age: Results from NHANES 1999-2004. Journal of Physical Activity and Health, 5(3), 347-358. doi: 10.1123/jpah.5.3.347 
International Federation on Ageing. (2012). Current and emerging issues facing older

Canadians. Retrieved from https://ifa.ngo/publication/social-inclusion-andintegration/current-and-emerging-issues-facing-older-canadians/

Joseph-Shehu, E. M., Ncama, B. P., Mooi, N., \& Mashamba-Thompson, T. P. (2019). The use of information and communication technologies to promote healthy lifestyle behaviour: A systematic scoping review. BMJ Open, 9(10), e029872. doi: 10.1136/bmjopen-2019029872

Kendrick, D., Orton, E., Lafond, N., Audsley, S., Maula, A., Morris, R.,...Iliffe, S. (2018). Keeping active: Maintenance of physical activity after exercise programmes for older adults. Public Health, 164, 118-127. doi: 10.1016/j.puhe.2018.08.003

Kontos, E. Z., Emmons, K. M., Puleo, E., \& Viswanath, K. (2010). Communication inequalities and public health implications of adult social networking site use in the United States. Journal of Health Communications, 15(3), 216-235. doi: 10.1080/10810730.2010.522689

Laranjo. L., Arguel, A., Neves, A. L., Gallagher, A. M., Kaplan, R., Mortimer, N.,...Lau, A. Y. S. (2015). The influence of social networking sites on health behavior change: A systematic review and meta-analysis. Journal of the American Medical Informatics Association, 22(1), 243-256. doi: 10.1136/amiajnl-2014-002841

Lindsay Smith, G., Banting, L., Eime, R., O’Sullivan, G., \& van Uffelen, G. Z. (2017). The association between social support and physical activity in older adults: A systematic review. International Journal of Behavioral Nutrition and Physical Activity, 14(1), 56. doi: 10.1186/s12966-017-0509-8 
Litwin, H. (2003). Social predictors of physical activity in later life: The contribution of socialnetwork type. Journal of Aging and Physical Activity, 11(3), 389-406. doi: 10.1123/japa.11.3.389

Loprinzi, P. D., \& Joyner, C. (2016). Source and size of emotional and financial-related social support network on physical activity behavior among older adults. Journal of Physical Activity and Health, 13(7), 776-779. doi: 10.1123/jpah.2015-0629

Maher, C. A., Lewis, L. K., Ferrar, K., Marshall, S., De Bourdeaudhuij, I., \& Vandelanotte, C. (2014). Are health behavior change interventions that use online social networks effective? A systematic review. Journal of Medical Internet Research, 16(2), 40. doi:10.2196/jmir.2952

Martire, L. M., Stephens, M. P., Mogle, J., Shulz, R., Brach, J., \& Keefe, F. J. (2013). Daily spousal influence on physical activity in knee osteoarthritis. Annals of Behavioral Medicine, 45(2), 213-223. doi: 10.1007/s12160-012-9442-x

McAuley, E., Jerome, G. J., Elavsky, S., Marquez, D. X., \& Ramsey, S. N. (2003). Predicting long-term maintenance of physical activity in older adults. Preventive Medicine, 37(2), 110-118. doi: 10.1016/S0091-7435(03)00089-6

McDonough, M. H., Sabiston, C. M., \& Ullrich-French, S. (2011). The development of social relationships, social support, and posttraumatic growth in a dragon boating team for breast cancer survivors. Journal of Sport \& Exercise Psychology, 33(5), 627-648. doi: $10.1123 /$ jsep.33.5.627

McMahon, S. K., Lewis, B., Oakes, J. M., Wyman, J. F., Guan, W., \& Rothman, A. J. (2017). Assessing the effects of interpersonal and intrapersonal behavior change strategies on 
physical activity in older adults: A factorial experiment. Annals of Behavioral Medicine, 51(3), 376-390. doi: 10.1007/s12160-016-9863-Z

Miles, J., \& Shevlin, M. (2001). Applying regression and correlation: A guide for students and researchers. Thousand Oaks, CA: SAGE Publications Inc.

Netz, Y., Wu, M.-J., Becker, B. J., \& Tenenbaum, G. (2005). Physical activity and psychological well-being in advanced age: A meta-analysis of intervention studies. Psychology and Aging, 20(2), 272-284. doi: 10.1037/0882-7974.20.2.272

ParticipACTION. (2019). 2019 ParticipACTION report card on physical activity for adults. Retrieved from https://www.participaction.com

Perrino, T., Brown, S. C., Huang, S., Hendricks Brown, C., Perez Gomez, G., Pantin, H., \& Szapocznik, J. (2011). Depressive symptoms, social support, and walking among Hispanic older adults. Journal of Aging and Health, 23(6), 974-993. doi: $10.1177 / 0898264311404235$

Petersen, J. M., Prichard, I., \& Kemps, E. (2019). A comparison of physical activity mobile apps with and without existing web-based social networking platforms: Systematic review. Journal of Medical Internet Research, 21(8), e12687. doi: 10.2196/12687

Raina, P. S., Wolfson, C., Kirkland, S. A., Griffith, L. E., Oremus, M., Patterson, C.,...Brazil, K. (2009). The Canadian longitudinal study on aging (CLSA). Canadian Journal on Aging, 28(3), 221-229. doi: 10.1017/S0714980809990055

Ranby, K. W., \& Aiken, L. S. (2016). Incorporating husband influences into a model of physical activity among older women. British Journal of Health Psychology, 21(3), 677-693. doi: 10.1111/bjhp.12195 
RAND Healthcare. (n.d.). Social support survey instrument scoring instructions. Retrieved from https://www.rand.org/health-care/surveys_tools/mos/social-support/scoring.html

Rennemark, M., Lindwall, M., Halling, A., \& Berglund, J. (2009). Relationships between physical activity and perceived qualities of life in old age: Results of the SNAC study. Aging and Mental Health, 13(1), 1-8. doi: 10.1080/13607860802154416

Richards, E. A., Franks, M. M., McDonough, M. H., \& Porter, K. (2018). 'Let’s move:' A systematic review of spouse-involved interventions to promote physical activity. International Journal of Health Promotion and Education, 56(1), 51-67. doi: $10.1080 / 14635240.2017 .1415160$

Scarapicchia, T. M. F., Amireault, S., Faulkner, G., \& Sabiston, C. M. (2016). Social support and physical activity participation among healthy adults: A systematic review of prospective studies. International Review of Sport and Exercise Psychology, 10(1), 50-83. doi: 10.1080/1750984X.2016.1183222

Sherbourne, C. D., \& Stewart, A. L. (1991). The MOS social support survey. Social Science \& Medicine, 32(6), 705-714. doi: 10.1016/0277-9536(91)90150-B

Shores, K. A., West, S. T., Theriault, D. S., \& Davison, E. A. (2009). Extra-individual correlates of physical activity attainment in rural older adults. The Journal of Rural Health, 25(2), 211-218. doi: 10.1111/j.1748-0361.2009.00220.x

Spiteri, K., Broom, D., Hassan Bekhet, A., Xerri de Caro, J., Laventure, B., \& Grafton, K. (2019). Barriers and motivators of physical activity participation in middle-aged and older adults: A systematic review. Journal of Aging and Physical Activity, 27(6), 929944. doi: 10.1123/japa.2018-0343 
Statistics Canada. (2017). Average time spent being physically active (Table 13-10-0339-01). Retrieved from https://www150.statcan.gc.ca/t1/tbl1/en/tv.action?pid=1310033901 Statistics Canada. (2019). Canadian internet use survey (Catalogue No. 11-001-X). Retrieved from https://www150.statcan.gc.ca/n1/daily-quotidien/191029/dq191029a-eng.htm

Tabachnick, B. G., \& Fidell, L. S. (2013). Using multivariate statistics (6th ed.). Boston, MA: Pearson.

Valtorta, N. K., Kanaan, M., Gilbody, S., \& Hanratty, B. (2016). Loneliness, social isolation and social relationships: What are we measuring? A novel framework for classifying and comparing tools. BMJ Open, 6(4), e010799. doi: 10.1136/bmjopen-2015-010799

Washburn, R. A., Smith, K. W., Jette, A. M., \& Janney, C. A. (1993). The physical activity scale for the elderly (PASE): Development and evaluation. Journal of Clinical Epidemiology, 46(2), 153-162. doi: 10.1016/0895-4356(93)90053-4

Williams, P., Barclay, L., \& Schmied, V. (2004). Defining social support in context: A necessary step in improving research, intervention, and practice. Qualitative Health Research, 14(7), 942-960. doi: 10.1177/1049732304266997

Yang, Q. (2017). Are social networking sites making health behavior change interventions more effective? A meta-analytic review. Journal of Health Communication, 22(3), 223-233. doi: $10.1080 / 10810730.2016 .1271065$

Yu, C.-Y., Hou, S.-I., \& Miller, J. (2018). Health for older adults: The role of social capital and leisure-time physical activity by living arrangement. Journal of Physical Activity and Health, 15(2), 150-158. doi: 10.1123/jpah.2017-0006 


\section{Structural Characteristics}

- Presence of Other People

- Marital/partner status

- Social network

- Interaction with Other People

- Social contact

- Online communication

- Social participation

\section{Functional Characteristics}

- Availability of Social Support and Support Behaviors

- Tangible support

- Affectionate support

- Emotional/informational support

- Positive social interaction

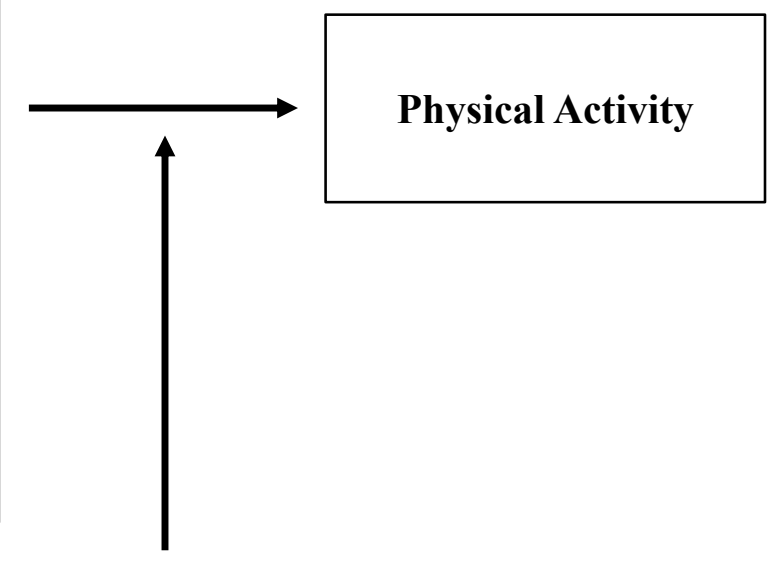

$$
\begin{aligned}
& \text { Demographic Indicators } \\
& \text { - Sex } \\
& \text { - Sexual orientation } \\
& \text { - Race/ethnicity } \\
& \text { - Indigenous identity } \\
& \text { - Livingrant } \\
& \text { - Caregiver } \\
& \text { - Income }
\end{aligned}
$$

Figure 1. Model of associations between forms of social support and physical activity, moderated by demographic indicators of groups at increased risk of social isolation. 
Table 1

Descriptive Statistics and Correlations Among Social Support, Groups at Increased Risk of Social Isolation, and Physical Activity

\begin{tabular}{|c|c|c|c|c|c|c|c|c|c|c|c|c|c|c|c|c|c|c|}
\hline & 1 & 2 & 3 & 4 & 5 & 6 & 7 & 8 & 9 & 10 & 11 & 12 & 13 & 14 & 15 & 16 & 17 & 18 \\
\hline 1. Marital/partner status & - & & & & & & & & & & & & & & & & & \\
\hline 2. Social network & $.13^{*}$ & - & & & & & & & & & & & & & & & & \\
\hline 3. Social contact & $-.02 *$ & $.14 *$ & - & & & & & & & & & & & & & & & \\
\hline 4. Online communication & -.01 & $.08 *$ & $.04 *$ & - & & & & & & & & & & & & & & \\
\hline 5. Social participation & $.05^{*}$ & $.19^{*}$ & $.15^{*}$ & .01 & - & & & & & & & & & & & & & \\
\hline 6. Tangible support & $.39 *$ & $.16^{*}$ & $.07 *$ & .00 & $.12 *$ & - & & & & & & & & & & & & \\
\hline 7. Affectionate support & $.37 *$ & $.16^{*}$ & $.09 *$ & $.03 *$ & $.17 *$ & $.63^{*}$ & - & & & & & & & & & & & \\
\hline $\begin{array}{l}\text { 8. Emotional/informational } \\
\text { support }\end{array}$ & $.21 *$ & $.18^{*}$ & $.09^{*}$ & $.02 *$ & $.17^{*}$ & $.63 *$ & $.65^{*}$ & - & & & & & & & & & & \\
\hline 9. Positive social interaction & $.29 *$ & $.19 *$ & $.09 *$ & .01 & $.21^{*}$ & $.63 *$ & $.71 *$ & $.73 *$ & - & & & & & & & & & \\
\hline 10. Sex & $-.28 *$ & $-.09 *$ & $.06^{*}$ & $.14 *$ & $.05^{*}$ & $-.15^{*}$ & $-.04 *$ & .01 & $-.07 *$ & - & & & & & & & & \\
\hline 11. Sexual orientation & $-.05^{*}$ & $-.03 *$ & -.01 & .00 & $-.02 *$ & $-.02 *$ & $-.04 *$ & -.00 & -.00 & $-.03 *$ & - & & & & & & & \\
\hline 12. Race/ethnicity & -.00 & .01 & $-.02 *$ & -.01 & .00 & $-.04 *$ & $-.04 *$ & $-.04 *$ & $-.05^{*}$ & $-.03 *$ & .01 & - & & & & & & \\
\hline 13. Indigenous identity & -.01 & $.03^{*}$ & .01 & $.03^{*}$ & .01 & $-.02 *$ & .00 & $-.02 *$ & -.01 & $.03 *$ & .00 & $.33^{*}$ & - & & & & & \\
\hline 14. Immigrant & $.02 *$ & $-.08 *$ & $-.02 *$ & $-.03 *$ & $.03 *$ & .01 & -.00 & .01 & -.01 & $-.04 *$ & .01 & $.19^{*}$ & $-.05^{*}$ & - & & & & \\
\hline 15. Living alone & $-.82 *$ & $-.12 *$ & $.05 *$ & .01 & $-.03 *$ & $-.40 *$ & $-.36 *$ & $-.21 *$ & $-.28 *$ & $.24 *$ & $.03 *$ & -.02 & .00 & $-.02 *$ & - & & & \\
\hline 16. Caregiver & $.03 *$ & $.09 *$ & $.04 *$ & $.02 *$ & $.07 *$ & $-.03 *$ & $.03 *$ & $.03 *$ & $.03 *$ & $.05^{*}$ & .01 & $-.02 *$ & .01 & $-.03 *$ & -.01 & - & & \\
\hline 17. Income & $.39 *$ & $.15^{*}$ & .00 & $-.05^{*}$ & $.09^{*}$ & $.22^{*}$ & $.20 *$ & $.16^{*}$ & $.20^{*}$ & $-.21^{*}$ & -.00 & $-.03 *$ & $-.05^{*}$ & $.07 *$ & $-.36^{*}$ & $.02 *$ & - & \\
\hline 18. Physical activity & $.14 *$ & $.16^{*}$ & $.05^{*}$ & .00 & $.13^{*}$ & $.09^{*}$ & $.09 *$ & $.09 *$ & $.11^{*}$ & $-.19^{*}$ & -.01 & -.01 & .00 & $.03 *$ & $-.14 *$ & $.10^{*}$ & $.16^{*}$ & - \\
\hline$N$ & 21,487 & 21,471 & 21,470 & 15,847 & 21,454 & 21,452 & 21,441 & 21,447 & 21,441 & 21,491 & 21,421 & 21,491 & 21,337 & 21,485 & 21,474 & 21,445 & 19,574 & 19,982 \\
\hline$M$ & .68 & 146.56 & 4.63 & .70 & 2.94 & 81.83 & 86.20 & 79.37 & 82.34 & .53 & .01 & .04 & .03 & .18 & .26 & .40 & 1.49 & 115.01 \\
\hline$S D$ & .47 & 98.58 & .64 & 1.02 & .69 & 21.69 & 20.40 & 20.84 & 20.64 & .50 & .11 & .19 & .16 & .38 & .44 & .49 & .91 & 58.38 \\
\hline Skewness & -.77 & .91 & -2.24 & 1.08 & -1.02 & -1.47 & -1.87 & -1.17 & -1.35 & -.14 & 8.71 & 4.84 & 5.84 & 1.68 & 1.10 & .41 & .67 & .77 \\
\hline$S E_{\text {skewness }}$ & .00 & .00 & .00 & .00 & .00 & .00 & .00 & .00 & .00 & .00 & .00 & .00 & .00 & .00 & .00 & .00 & .00 & .00 \\
\hline Kurtosis & -1.41 & .32 & 7.51 & -.30 & 2.60 & 1.87 & 3.47 & 1.12 & 1.73 & -1.98 & 73.91 & 21.39 & 31.15 & .83 & -.79 & -1.83 & .55 & 1.43 \\
\hline$S E_{\text {kurtosis }}$ & .00 & .00 & .00 & .00 & .00 & .00 & .00 & .00 & .00 & .00 & .00 & .00 & .00 & .00 & .00 & .00 & .00 & .00 \\
\hline Scale range & $0-1$ & $0-650$ & $0-5$ & $0-4$ & $0-4$ & $0-100$ & $0-100$ & $0-100$ & $0-100$ & $0-1$ & $0-1$ & $0-1$ & $0-1$ & $0-1$ & $0-1$ & $0-1$ & $0-4$ & $0-512$ \\
\hline
\end{tabular}

$* p<.05$ 
Table 2

Associations Among Social Support, Groups at Increased Risk of Social Isolation, and Physical Activity

\begin{tabular}{|c|c|c|c|c|}
\hline & \multicolumn{2}{|c|}{$\begin{array}{c}\text { Model 1 } \\
\left(R^{2}=.21^{*}, S E=.01\right)\end{array}$} & \multicolumn{2}{|c|}{$\begin{array}{c}\text { Model 2 } \\
\left(R^{2}=.21^{*}, S E=.01\right)\end{array}$} \\
\hline & $b$ & $S E$ & $b$ & $S E$ \\
\hline \multicolumn{5}{|l|}{ Predictor Variables } \\
\hline Marital/partner status & $-5.60 *$ & 2.16 & 2.24 & 2.73 \\
\hline Social network & $.04 *$ & .01 & $.04 *$ & .01 \\
\hline Social contact & $2.93^{*}$ & .91 & $2.89 *$ & .91 \\
\hline Online communication & .44 & .63 & -2.29 & 1.28 \\
\hline Social participation & $7.92 *$ & .92 & $9.43 *$ & 1.12 \\
\hline Tangible support & $-.08^{*}$ & .03 & $-.15^{*}$ & .05 \\
\hline Affectionate support & .04 & .04 & .02 & .04 \\
\hline Emotional/informational support & .02 & .04 & .02 & .04 \\
\hline Positive social interaction & -.01 & .05 & .00 & .04 \\
\hline \multicolumn{5}{|l|}{ Covariates } \\
\hline Age & $-1.91 *$ & .11 & $-1.93^{*}$ & .11 \\
\hline Education & -.60 & .53 & -.64 & .53 \\
\hline Body mass index & $-1.08 *$ & .11 & $-1.09 *$ & .11 \\
\hline General health & $7.99 *$ & .72 & $7.97 *$ & .72 \\
\hline General mental health & $-1.51 *$ & .73 & $-1.55^{*}$ & .73 \\
\hline Depression & -.13 & .14 & -.11 & .14 \\
\hline Chronic conditions & $-1.32 *$ & .21 & $-1.35^{*}$ & .21 \\
\hline Pain and discomfort & 1.80 & 1.22 & 1.82 & 1.22 \\
\hline Injuries & 2.62 & 1.86 & 2.58 & 1.85 \\
\hline Falls & $-5.26^{*}$ & 1.65 & $-5.36^{*}$ & 1.65 \\
\hline Smoking habits & $-.88 *$ & .45 & $-.90 *$ & .45 \\
\hline Alcohol use & 1.46 & .79 & 1.47 & .79 \\
\hline Social inequality & $1.35^{*}$ & .30 & $1.34^{*}$ & .30 \\
\hline Retirement status & $-11.95^{*}$ & 1.06 & $-11.95^{*}$ & 1.06 \\
\hline Barriers to more social activities & $1.42 *$ & .62 & $1.52 *$ & .63 \\
\hline Barriers to more physical activities & $-4.86^{*}$ & .72 & $-4.95 *$ & .72 \\
\hline \multicolumn{5}{|l|}{ Moderator Variables } \\
\hline Sex & $-18.42 *$ & 1.21 & $-10.18 *$ & 1.96 \\
\hline Sexual orientation & $-12.36^{*}$ & 3.88 & $-10.97 *$ & 3.96 \\
\hline Race/ethnicity & $-8.61 *$ & 3.14 & $-8.80^{*}$ & 3.16 \\
\hline Indigenous identity & $9.34 *$ & 3.68 & $9.62 *$ & 3.67 \\
\hline Immigrant & $3.44 *$ & 1.44 & $3.41 *$ & 1.43 \\
\hline Living alone & $-10.15^{*}$ & 2.20 & -3.80 & 6.61 \\
\hline Caregiver & $9.01 *$ & 1.11 & $8.89 *$ & 1.10 \\
\hline Income & .58 & .79 & -.45 & .90 \\
\hline \multicolumn{5}{|l|}{ Interaction Terms } \\
\hline Marital/partner status x Sex & - & - & $-11.42 *$ & 2.40 \\
\hline Social participation $\mathrm{x}$ Living alone & - & - & $-5.80^{*}$ & 1.79 \\
\hline Tangible support $\mathrm{x}$ Living alone & - & - & $.15^{*}$ & .05 \\
\hline Online communication x Income & - & - & $1.65 *$ & .72 \\
\hline
\end{tabular}

Note: In Model 1, the moderators were included as control variables.

$* p<.05, b=$ unstandardized beta 
a)

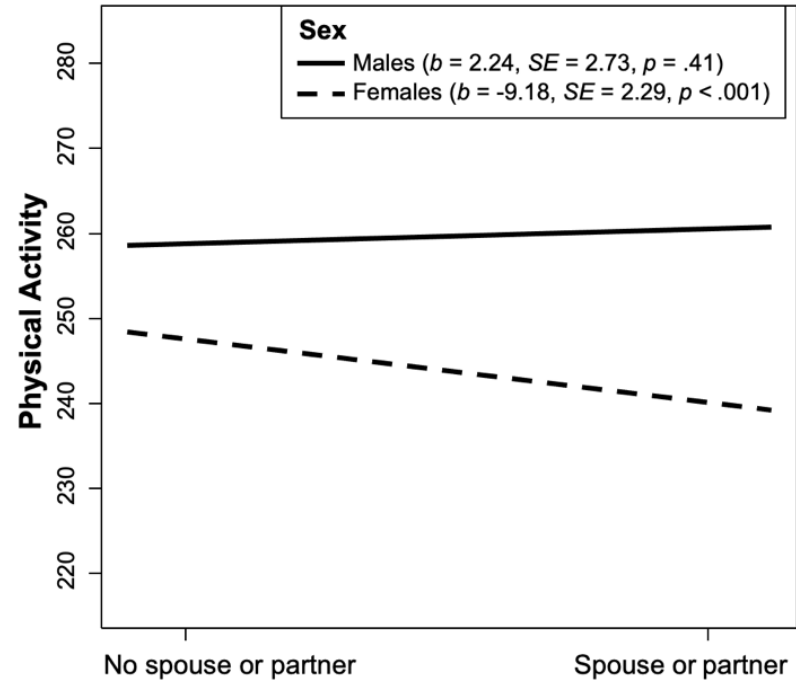

Marital/Partner Status

c)

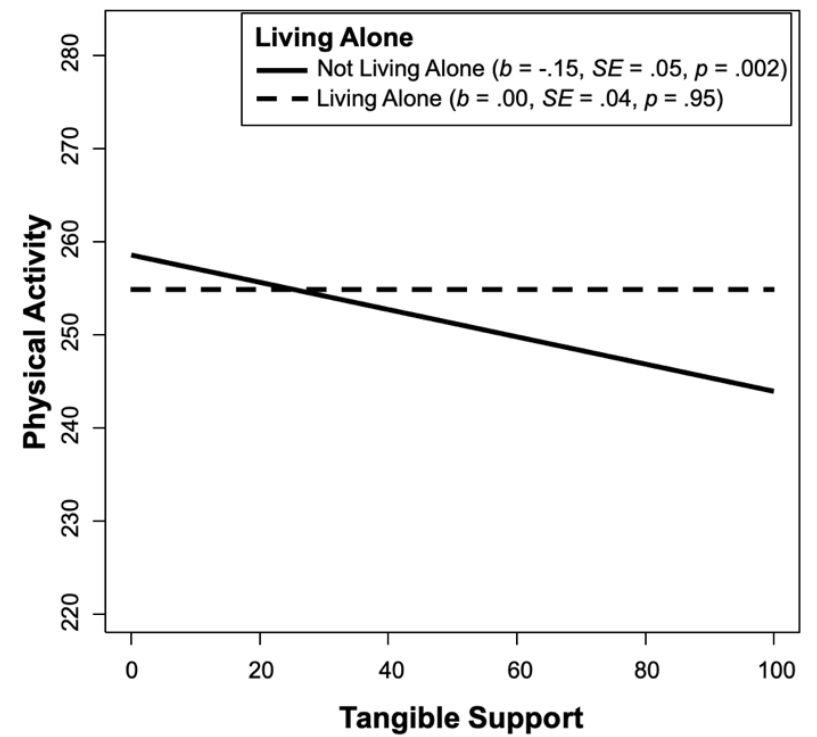

b)

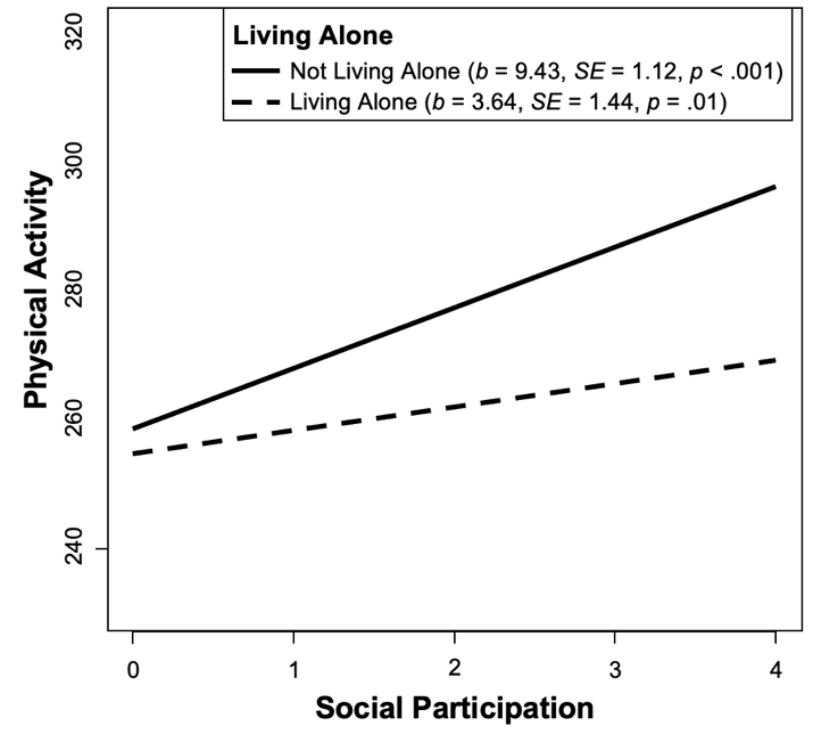

d)

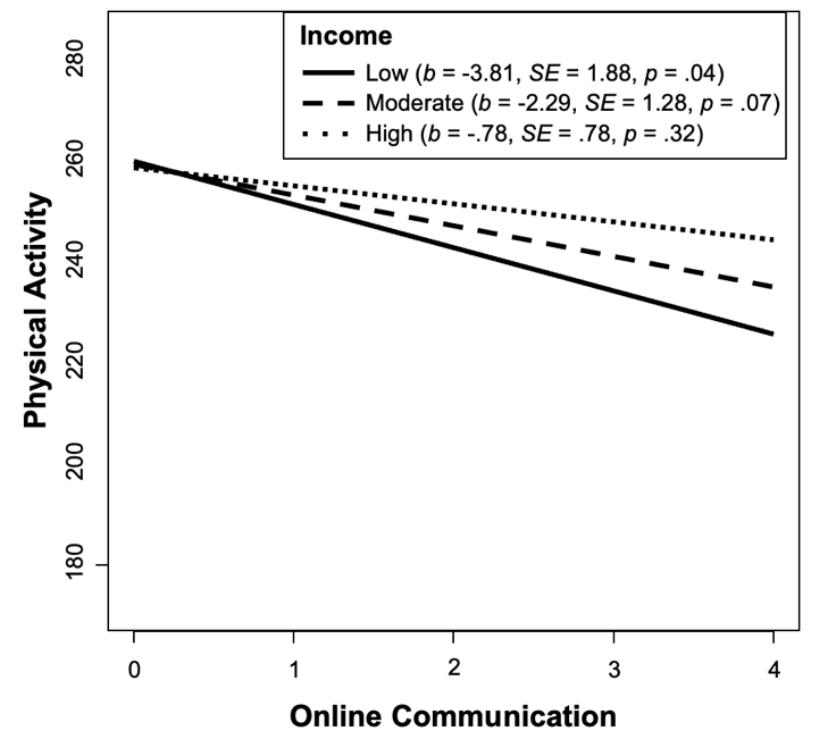

Figure 2. Significant interaction effects on physical activity. 